\title{
Is there a solar signal in lower stratospheric water vapour?
}

\author{
T. Schieferdecker, S. Lossow, G. P. Stiller, and T. von Clarmann \\ Karlsruhe Institute of Technology, Institute for Meteorology and Climate Research, Karlsruhe, Germany \\ Correspondence to: T. von Clarmann (thomas.clarmann@kit.edu)
}

Received: 13 March 2015 - Published in Atmos. Chem. Phys. Discuss.: 24 April 2015

Revised: 6 August 2015 - Accepted: 18 August 2015 - Published: 2 September 2015

\begin{abstract}
A merged time series of stratospheric water vapour built from the Halogen Occultation Instrument (HALOE) and the Michelson Interferometer for Passive Atmospheric Sounding (MIPAS) data between $60^{\circ} \mathrm{S}$ and $60^{\circ} \mathrm{N}$ and 15 to $30 \mathrm{~km}$ and covering the years 1992 to 2012 was analysed by multivariate linear regression, including an 11-year solar cycle proxy. Lower stratospheric water vapour was found to reveal a phase-shifted anti-correlation with the solar cycle, with lowest water vapour after solar maximum. The phase shift is composed of an inherent constant time lag of about 2 years and a second component following the stratospheric age of air. The amplitudes of the water vapour response are largest close to the tropical tropopause (up to $0.35 \mathrm{ppmv}$ ) and decrease with altitude and latitude. Including the solar cycle proxy in the regression results in linear trends of water vapour being negative over the full altitude/latitude range, while without the solar proxy, positive water vapour trends in the lower stratosphere were found. We conclude from these results that a solar signal seems to be generated at the tropical tropopause which is most likely imprinted on the stratospheric water vapour abundances and transported to higher altitudes and latitudes via the Brewer-Dobson circulation. Hence it is concluded that the tropical tropopause temperature at the final dehydration point of air may also be governed to some degree by the solar cycle. The negative water vapour trends obtained when considering the solar cycle impact on water vapour abundances can possibly solve the "water vapour conundrum" of increasing stratospheric water vapour abundances despite constant or even decreasing tropopause temperatures.
\end{abstract}

\section{Introduction}

Water vapour is one of the Earth's most important greenhouse gases, having the strongest long-wave radiative forcing effect on the atmosphere (Kiehl and Trenberth, 1997). An increase of water vapour in the lower stratosphere leads to a warmer troposphere, further affecting global surface temperatures (Manabe and Strickler, 1964; Solomon et al., 2010). Water vapour concentrations, particularly near the tropical tropopause, strongly influence surface climate (Riese et al., 2012), and increasing stratospheric concentrations intensify ozone loss in this atmospheric region (Stenke and Grewe, 2005). For these reasons it is of major importance to understand its trends and fluctuations on a global scale. It is generally accepted that the tropical tropopause temperature is the main driver of the amount of water vapour transported from the troposphere into the stratosphere (Fueglistaler et al., 2009). However, admittedly, the analysis of stratospheric and upper tropospheric water vapour trends is challenging, given the fact that only few decades of global data are available. Particular issues of the ongoing discussion are the apparent inconsistencies between the time series measured above Boulder with frost point hygrometers (Hurst et al., 2011) and global satellite data (Hegglin et al., 2014); the sudden decrease in lower stratospheric water vapour mixing ratios observed in 2000/2001 (Rosenlof and Reid, 2008; Randel et al., 2006) and in 2011/2012 (Urban et al., 2014) as well as missing processes that constrain stratospheric water vapour (besides tropical tropopause layer - TTL - temperature conditions and transport) (Rosenlof et al., 2001; Fueglistaler et al., 2013); a potential steep increase around 1990 that puts into question if a decoupling of stratospheric water vapour and tropical tropopause temperature trends on short timescales is possible (Fueglistaler, 2012); the role of deep and overshooting convection for the moistening of the stratosphere 
(Corti et al., 2008; Schiller et al., 2009); and finally the role of the western tropical Pacific cold trap for the transport of water vapour into the stratosphere (Holton and Gettelmann, 2001; Fueglistaler et al., 2005).

In this work, stratospheric $\mathrm{H}_{2} \mathrm{O}$ records from the Halogen Occultation Instrument (HALOE) (Russell III et al., 1993) and the Michelson Interferometer for Passive Atmospheric Sounding (MIPAS, Fischer et al., 2008) have been used to analyse the lower stratospheric $\mathrm{H}_{2} \mathrm{O}$ time series since 1992 . The main characteristics of these two instruments are summarized in Sect. 2. These data sets have been harmonized in order to produce a homogeneous $\mathrm{H}_{2} \mathrm{O}$ record (Sect. 3). This merged long-term record has then been analysed by means of multi-linear regression analysis (Sect. 4) in order to identify the processes controlling the variability of stratospheric water vapour. In Sect. 5 the results are critically discussed and put into context of results from other research groups. Section 6 aims at estimating the implications of our results for future research.

\section{The empirical basis}

While a large number of altitude-resolved $\mathrm{H}_{2} \mathrm{O}$ records inferred from limb emission or occultation measurements (e.g. Hegglin et al., 2013), as well as merged data sets (e.g. Froidevaux et al., 2015) exist, for this study, stratospheric $\mathrm{H}_{2} \mathrm{O}$ records from HALOE (Russell III et al., 1993) and MIPAS (Fischer et al., 2008) have been used. The reason is that both these instruments provided $\mathrm{H}_{2} \mathrm{O}$ measurements at nearglobal coverage and that their mission periods were nicely complementary, with a sufficiently long overlap period for data harmonization. Inclusion of further instruments would have implied an additional risk of artefacts due to unknown differences in data characteristics.

\subsection{HALOE}

The Halogen Occultation Instrument (HALOE) (Russell III et al., 1993) is a solar occultation infrared radiometer for the measurement of composition and temperature of the middle atmosphere. It recorded atmospherically attenuated solar radiance in four channels between 996 and $4081 \mathrm{~cm}^{-1}$. HALOE was a payload of the Upper Atmosphere Research Satellite (UARS) and was operational from 11 October 1991 to 21 November 2005. With about 15 UARS orbits per day and one sunrise and one sunset measurement per orbit, up to about 10800 vertical profiles of each target quantity could be measured per year. One of the target species measured by HALOE is $\mathrm{H}_{2} \mathrm{O}$, for which an altitude resolution of 2 to $3 \mathrm{~km}$ is reported (Russell III, 1995; Hegglin et al., 2013). In this work we use HALOE data version 19, which was discussed in Kley et al. (2000) and Hegglin et al. (2013), where a small dry bias is reported for the altitude range relevant to this paper. Problems with HALOE water vapour retrievals of an ear- lier data version due to aerosol have been reported by Hervig et al. (1995) but problematic cases discussed there were no longer present in the data set we used and thus seem to have been removed (Steele and Turco, 1997). During its 14-year lifetime, HALOE $\mathrm{H}_{2} \mathrm{O}$ measurements were frequently validated (Harries et al., 1996; Dessler and Kim, 1999). No significant instrumental drifts were found by Nedoluha et al. (2003) when they compared HALOE time series with those from various independent measurements.

\subsection{MIPAS}

The Michelson Interferometer for Passive Atmospheric Sounding (MIPAS, Fischer et al., 2008) is a limb emission mid-infrared Fourier transform spectrometer designed for limb-sounding of the composition and temperature of the middle atmosphere. Its spectral coverage is 685 to $2410 \mathrm{~cm}^{-1}$. MIPAS was a core instrument of the Envisat research satellite which was launched into a polar sunsynchronous orbit on 1 March 2002. The MIPAS data record covers the time from July 2002 to April 2012, with a data gap in 2004. In the first part of the mission (2002-2004) MIPAS recorded high-resolution (HR) spectra (apodized resolution $0.05 \mathrm{~cm}^{-1}$ ). In March 2004 operation was interrupted due to problems with the interferometer slide until in January 2005 operation was resumed, however at reduced spectral resolution (RR, $0.121 \mathrm{~cm}^{-1}$ after apodization). In turn, the shorter optical path difference associated with the reduced spectral resolution measurements allowed for a denser tangent altitude grid and along with this a better vertical resolution, which is $4.0 \mathrm{~km}$ in the middle stratosphere as opposed to $4.5 \mathrm{~km}$ for the high spectral resolution measurements. With 14.4 orbits per day and 74 (96) limb scans per orbit in HR (RR) mode, MIPAS recorded 1065 (1382) profiles per day.

The MIPAS $\mathrm{H}_{2} \mathrm{O}$ data used here were produced with a dedicated research processor developed and operated by the Institute of Meteorology and Climate Research (IMK) team in Karlsruhe, Germany, in cooperation with the Instituto de Astrofísica de Andalucía-CSIC in Granada, Spain (von Clarmann et al., 2003). The MIPAS $\mathrm{H}_{2} \mathrm{O}$ retrieval and validation is reported in Milz et al. (2005, 2009), von Clarmann et al. (2009) and Stiller et al. (2012a). In this paper we have used data versions V5h_H2O_20 for the HR measurements and V5r_H2O_220/221 for the RR measurements. Versions 220 and 221 are scientifically equivalent but carry different version numbers to maintain traceability of data processing details.

The MIPAS instrument stability has been assessed (Michael Kiefer, personal communication, 2015). A possible drift due to detector-aging and resulting changes of its non-linear response was estimated at approximately -0.05 ppmv decade $^{-1}$. This is in agreement with, e.g. Nedoluha et al. (2013) who did not find any larger relative drifts between the Water Vapor Millimeter-wave Spectrometer and various satellite-borne instruments including MIPAS. 


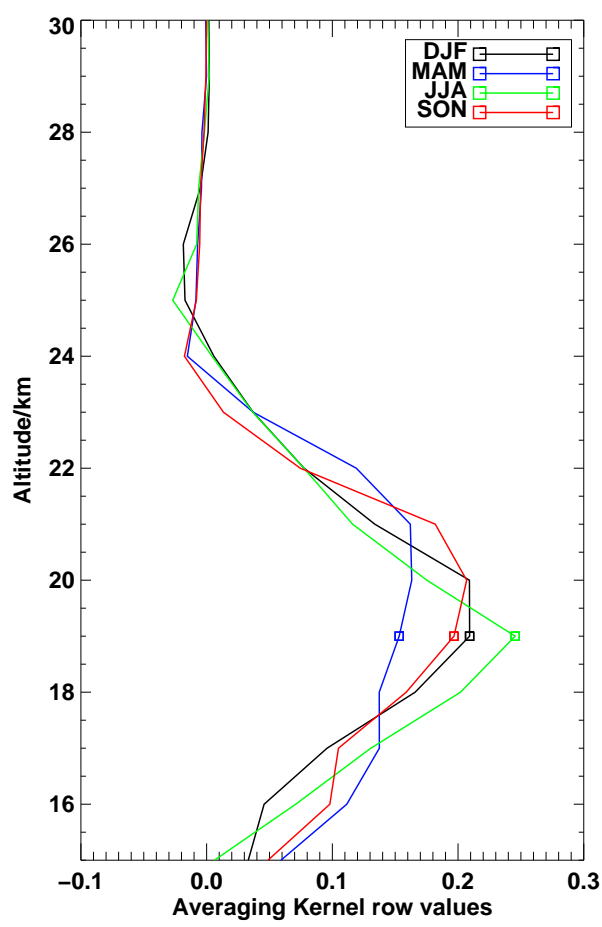

Figure 1. $\mathrm{H}_{2} \mathrm{O}$ averaging kernels for December, January, February (DJF, black line), March, April, May (MAM, blue line), July, July, August (JJA, green line) and September, October, November (red line) at $19 \mathrm{~km}$ nominal altitude, $0-10^{\circ} \mathrm{S}$. It should be noted that the kernels refer to $\log (\mathrm{vmr})$, not vmr.

\section{The harmonized $\mathrm{H}_{2} \mathrm{O}$ record}

The combined HALOE-MIPAS $\mathrm{H}_{2} \mathrm{O}$ record covers more than 2 decades. Both the HALOE and the MIPAS data sets have been filtered according to provider-defined criteria: trip angle and lockdown angle issues for HALOE; and low averaging kernel diagonal values and visibility flag for MIPAS. Further, in order to avoid artefacts, homogenization of the data is important. The following issues have been tackled: (1) artefacts due to Pinatubo aerosol; (2) different altitude resolution and (3) biases and stability.

\subsection{Pinatubo}

The eruption of Mount Pinatubo on 15 June 1991 brought enormous amounts of aerosol into the stratosphere. This aerosol layer affected the radiative transfer of solar radiation through the atmosphere and led to artefacts in the HALOE analysis (Steele and Turco, 1997). Thus, HALOE data from the first 5 months have been discarded and data since March 1992 have been used.

\subsection{Altitude resolution}

For harmonization with respect to altitude resolution we use the method suggested by Connor et al. (1994) and described

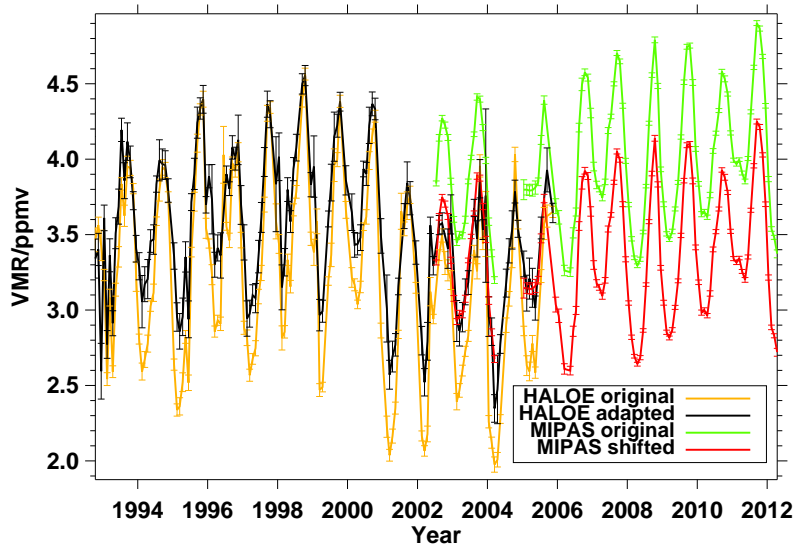

Figure 2. $\mathrm{H}_{2} \mathrm{O}$ time series of the original (green) and de-biased (red) MIPAS data, HALOE (yellow) and HALOE after application of the MIPAS averaging kernels (black). The altitude/latitude bin at $20^{\circ} \mathrm{S}-20^{\circ} \mathrm{N}, 17-18 \mathrm{~km}$ is shown as an example.

in detail for application to MIPAS profiles by Stiller et al. (2012a). The better resolved HALOE profile is degraded with a representative MIPAS averaging kernel (see Rodgers, 2000, for a detailed discussion of the concept of averaging kernels) to provide a $\mathrm{HALOE} \mathrm{H}_{2} \mathrm{O}$ profile as MIPAS with its inferior altitude resolution would have seen it. Representative MIPAS averaging kernels were constructed for each latitude band of 10 degrees coverage and for each season (Fig. 1). Details of the construction of representative averaging kernels are reported in Schieferdecker (2015). Along with this degradation, HALOE data were resampled on the MIPAS altitude grid which has a $1 \mathrm{~km}$ grid width in the altitude range relevant to this study.

Figure 2 shows the combined time series both with the original HALOE data (yellow curve) and with the degraded HALOE data (black curve). It is obvious that the amplitude of the annual cycle in HALOE data is much larger than in the MIPAS data (green and red curve). The reason is roughly this: in the case of MIPAS, the unknown variable in the retrieval is not the mixing ratio of $\mathrm{H}_{2} \mathrm{O}$ but its logarithm. Thus the Jacobian of the radiative transfer model depends directly on the mixing ratio (vmr) of water vapour, even if radiative transfer is linear with respect to vmr. For larger $\mathrm{H}_{2} \mathrm{O}$ abundances the Jacobian is larger and thus the weight of the constraint term in the retrieval is smaller and the altitude resolution is better. From this follows that MIPAS resolves the hygropause better in the wet season than in the dry season. This leads to the asymmetric distortion of the annual cycle, seen when comparing the black and the yellow curve in Fig. 2. Application of the season-dependent MIPAS averaging kernels to HALOE data as described above leads to a HALOE time series which is almost perfectly comparable to that of MIPAS. This pronounced effect proves that the direct analysis of MIPAS $\mathrm{H}_{2} \mathrm{O}$ time series without consideration of averaging kernels is prone to false conclusions. 


\subsection{De-biasing}

The MIPAS-HALOE overlap period from July 2002 to August 2005 allows for de-biasing of MIPAS with respect to HALOE. This de-biasing was performed independently for the MIPAS HR and RR data, because these two data sets rely on different processing schemes and thus could theoretically have different characteristics. By the independent de-biasing of each of the two MIPAS data sets with respect to HALOE, biases between both the MIPAS data sets are also removed implicitly. These, however, were found to be small anyway.

Three different approaches to determine the bias were tested, one relying on coincident measurements, the other relying on latitudinal mean values, and the third minimizing the root mean square difference of the MIPAS and HALOE time series during the overlap period. The third method proved to be most robust and was finally selected. The other two candidate approaches suffered from sparse statistics or sampling artefacts, respectively. De-biasing was performed separately for each $10^{\circ}$ latitude bin between $80^{\circ} \mathrm{N}$ and $80^{\circ} \mathrm{S}$ and for each altitude of the MIPAS vertical grid. An example is shown in Fig. 2 (red curve). The merged time series used for our further analysis is represented by black and red lines. Within the overlap period a weighted average of the homogenized HALOE and MIPAS data has been used.

\section{Regression analysis}

In order to better understand the temporal variation of $\mathrm{H}_{2} \mathrm{O}$ in the lower stratosphere, a multilinear regression analysis of the time series was performed for each altitude/latitude bin. The regression model proposed by von Clarmann et al. (2010) and extended by Stiller et al. (2012b) was used for this purpose. It optionally considers the use of the full data error covariance matrix and represents the local volume mixing ratio of water vapour as a function of time using a constant term, a linear trend, amplitudes of various harmonic oscillations and user defined proxies as fit variables. Piecewise linear trends as derived by the cumulative sum method following Reinsel (2002) or Jones et al. (2009) were tried but finally not considered because they merely help to describe but not to explain the temporal variation. For each harmonic, both the coefficients of the sine and the cosine term are fitted, which together control both the phase and the amplitude of the harmonic. The correlated part of the error is attributed to variations that are not described in the regression model. The correlation coefficients of this model error term are obtained from the residuals of a first iteration where only the standard errors of the monthly mean mixing ratios were considered as data errors. The amplitude of this additional error term was adjusted iteratively to comply with $\chi^{2}$ statistics (von Clarmann et al., 2010).

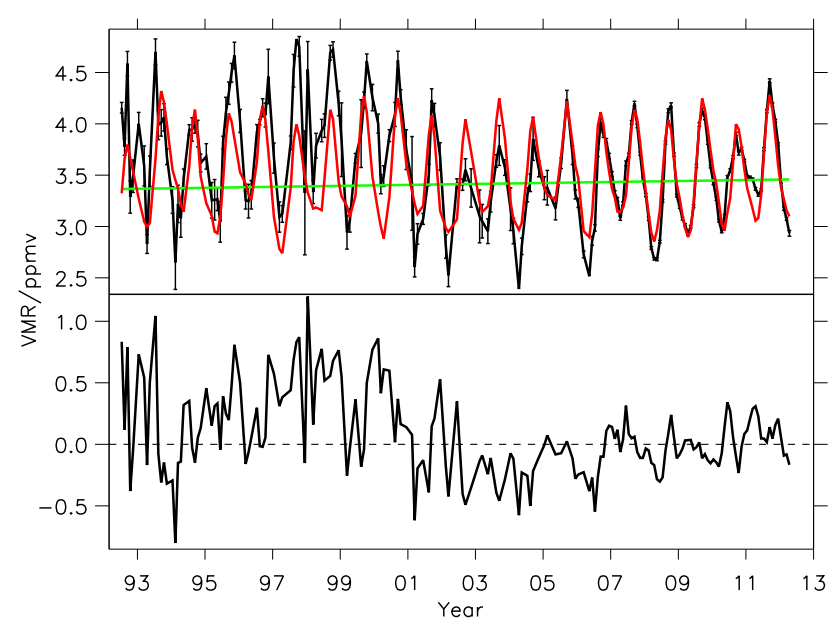

Figure 3. The merged time series (top panel, black curve) with the standard errors of the data (black) and the best fitting standard regression model (top panel, red curve) and the linear term of the regression (green line). In the lower panel the residual time series between the measured data and the fitted regression model is shown. The latitude bin of $0-10^{\circ} \mathrm{S}$ is shown for an altitude of $17 \mathrm{~km}$ as an example. The residual ( $\mathrm{rms}=0.35 \mathrm{ppmv}$ ) appears to have a systematic harmonic component with a period of about 11 years.

\subsection{The standard regression}

Besides the constant and linear term, the annual cycle and its first three overtones (wavenumbers two, three, and four waves per year) were considered. Wavenumber two represents the semi-annual oscillations, and wavenumbers two to four help to better model the annual cycle when it is not perfectly harmonic. The following proxies were considered:

The quasi-biennial oscillation (QBO) was parametrized using Singapore winds at 30 and $50 \mathrm{hPa}$, as obtained from the Institut für Meteorologie of the Freie Universität Berlin, (http://www.geo.fu-berlin.de/met/ag/strat/produkte/ qbo). Between the winds at these pressure levels, there is a phase shift of approximately $\frac{\pi}{2}$. Thus, fitting coefficients of both of these gives access to the approximate phase and amplitude of the QBO signal (cf., e.g. Kyrölä et al., 2004).

For the El Niño-Southern Oscillation (ENSO) signal, the Multivariate ENSO Index (MEI) (http://www.esrl.noaa.gov/ $\mathrm{psd} / \mathrm{enso} / \mathrm{mei} / \mathrm{index} . \mathrm{html}$ ) was used as a proxy. Since this data set refers to a tropical surface pressure level, a time lag was considered to make the proxy representative for the stratospheric latitudes and altitudes considered here. To estimate the time lag, temporally averaged stratospheric mean age of air data from Stiller et al. (2012b) were used.

In the fitted time series there are pronounced systematic residuals. Some of them are related to an apparent discontinuity in the water vapour abundance in 2001, the well-known millennium water vapour drop (Randel et al., 2006; Urban et al., 2014) but the fits are unsatisfactory in the entire period before 2007. The residual time series appears to be domi- 


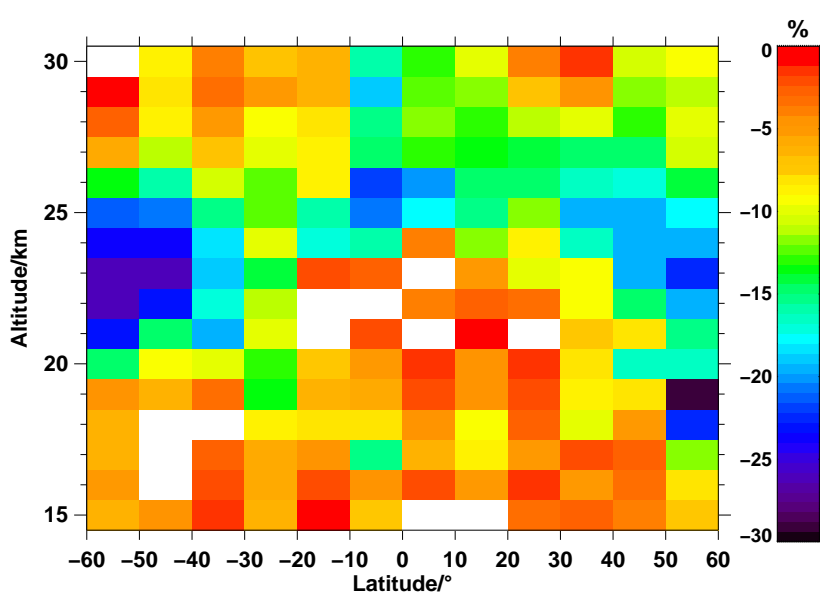

Figure 4. The root mean square improvement of the fit residual with respect to the standard approach, gained by the inclusion of the solar cycle approximated by harmonic parametrization as described under Approach 1 in Sect. 4.2. White bins are positive values, i.e. deterioration of the fit.

nated by a systematic harmonic feature of a period length of about 11 years. Figure 3 shows the fit of the time series at $17 \mathrm{~km}$ altitude in the latitude bin $0-10^{\circ} \mathrm{S}$ as an example.

\subsection{Consideration of the solar cycle}

The fit residuals obtained by the regression analysis described in the previous section resemble a harmonic with a period of about 11 years. Besides, strong $\mathrm{H}_{2} \mathrm{O}$ decreases are visible in 1994 and 2001. The period of 11 years suggests also considering the solar cycle in the regression model. Two approaches have been tried:

Approach 1: the solar cycle was modelled by a harmonic of 127 months with an overtone of 63 months (cf. Cunnold et al., 2004). Fitting of the related sine and cosine coefficients gave access to the amplitude and phase of the solar signal. Consideration of the solar term improves the fits within $60^{\circ} \mathrm{S}-60^{\circ} \mathrm{N}$ in $92 \%$ of the altitude/latitude bins (Fig. 4). The improvement is most pronounced at altitudes around $25 \mathrm{~km}$ and reaches $20-30 \%$ in some altitude/latitude bins. The time series at $0-10^{\circ} \mathrm{S}, 17 \mathrm{~km}$ altitude is shown as an example how the new regression model fits the time series (Fig. 5). While both the $\mathrm{H}_{2} \mathrm{O}$ minimum in 1994 and the so-called millennium drop in 2001 are still visible in the residual data and still calls for explanation, the majority of the systematic residuals have disappeared and the general shape of the time series is nicely reproduced by the regression model. This result suggests that the solar cycle might indeed partially control lower stratospheric water vapour.

Approach 2: alternatively to the treatment with harmonics, the solar cycle has been fitted using the radio flux index at a wavelength of $10.7 \mathrm{~cm}$ (F10.7) as a proxy. This index, which is available via the Solar and Heliospheric Observatory (SOHO, http://sohowww.nascom.nasa.gov/sdb/ydb/indices_

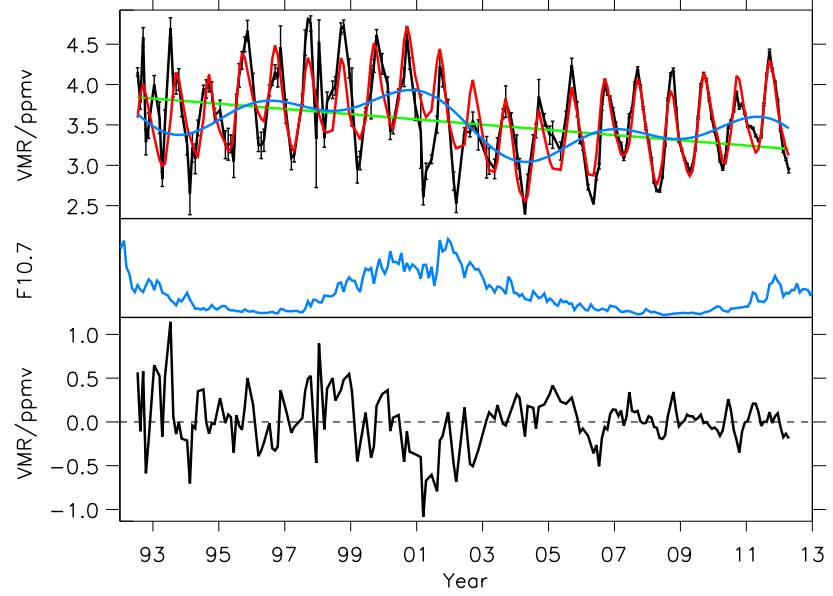

Figure 5. Top panel: Fitted regression model with solar cycle approximated by harmonic parametrization as described under Approach 1 in Sect. 4.2. The blue curve is the fitted contribution of these harmonics and the green line is the linear component. The middle panel (blue curve) shows the original solar cycle F10.7 parametrization in arbitrary units. In the lower panel the residual time series between the measured data and the fitted regression model is shown. The rms for this fit is $0.30 \mathrm{ppmv}$. For further details, see Fig. 3.

flux_raw/Penticton_Observed/monthly/MONTHPLT.OBS) is proportional to solar activity. Since it is not a priori clear which solar-terrestrial processes might control the $\mathrm{H}_{2} \mathrm{O}$ content of the stratosphere and where exactly they happen, and how long the processed air travels through the stratosphere before it is observed, the phase shift obtained from Approach 1 (approximation of the solar cycle effect by harmonic functions) has also been applied to the F10.7 proxy. Delayed anti-correlation (lowest water vapour for solar maximum, shifted by several months, depending on altitude and latitude) provided the best results. The improvements over the regression without the solar term are shown in Fig. 6. While the improvements are less pronounced in some of the bins than for Approach 1, this approach seems to be more adequate for the inner tropical lowermost stratosphere. For $95 \%$ of the bins within $60^{\circ} \mathrm{S}-60^{\circ} \mathrm{N}$ the fit has been improved compared to the standard approach without solar cycle. The altitude/latitude bin at $0-10^{\circ} \mathrm{S}, 17 \mathrm{~km}$ is shown as an example (Fig. 7). In this particular case, the residual due to the millennium drop is less pronounced than in the case with the regression model using the harmonic representation of the solar cycle effect, but it is still visible.

Both approaches reveal a strong relation between the water vapour abundances and the solar cycle. The correlation is phase-shifted in a sense that lowest water vapour abundances are seen a couple of years after the solar maximum (see Fig. 7 as an example). 


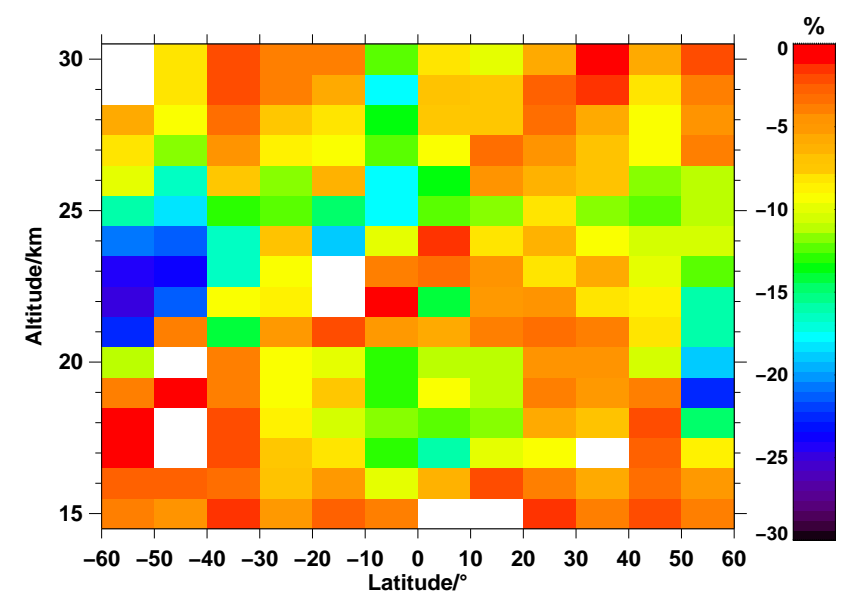

Figure 6. The root mean square improvement of the fit residual with respect to the standard approach gained by the inclusion of the solar cycle approximated by the F10.7 proxy as described under Approach 2 in Sect. 4.2. White bins are positive values, i.e. deterioration of the fit.

The amplitudes of the solar component in the regression model are shown in Fig. 8 for both the harmonic (top panel) and the F10.7 (bottom panel) parametrization. While the amplitudes associated with the harmonic approach are larger, the altitude/latitude distributions of the amplitudes associated with each approach have the same structure. Largest effects are seen around the tropical tropopause region, and smallest in the southern mid-latitudinal middle stratosphere.

The propagation of the data errors through the regression model leads to uncertainties of these amplitudes of generally less than $2 \%$ within the tropical pipe and less than $5 \%$ outside. Fit residuals, however, are not compliant with $\chi^{2}$ statistics, indicating that the regression model, even with the solar term included, is less than perfect and does not fully describe the entire variation of stratospheric $\mathrm{H}_{2} \mathrm{O}$. Analysis of the fit residuals and consideration of resulting estimates of correlated model errors suggests an uncertainty in the order of 15 to $50 \%$ over a larger part of the altitude/latitude range, with highest and contiguous significance $(15-25 \%$ relative error of the amplitude) in the tropical tropopause range. This provides good confidence in the results.

The phase shift of the solar signal (Fig. 9) is an interesting result in itself because it helps to determine where in the atmosphere the solar-terrestrial processes controlling the stratospheric $\mathrm{H}_{2} \mathrm{O}$ content might take place. The phase shift $\alpha$ - which, for all altitude/latitude bins, represents a delay of the negative response of water vapour to the original solar cycle - is about 40 months at about $18 \mathrm{~km}$ altitude and 45 to 50 months at about $22 \mathrm{~km}$ altitude in the inner tropics. This implies that a certain phase $\alpha$ which is seen at a certain time at, e.g. $18 \mathrm{~km}$ altitude, is observed 5 to 10 months later at $22 \mathrm{~km}$ altitude. We compare this with the temporally averaged mean age of stratospheric air distribution $(\operatorname{age}(\phi, z))$

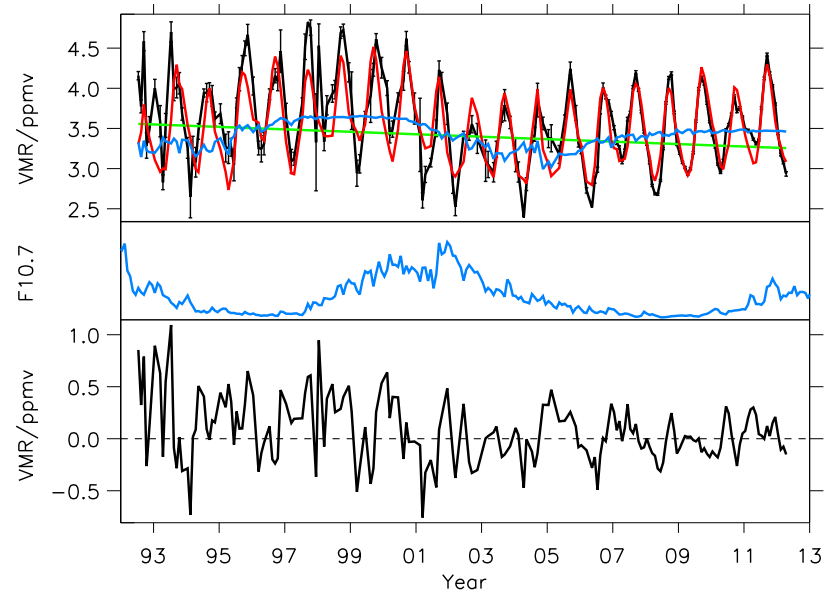

Figure 7. Top panel: fitted regression model with solar cycle approximated by the F10.7 proxy as described under Approach 2 in Sect. 4.2. The blue curve is the fitted solar signal contribution with the F10.7 proxy. The middle panel (blue curve) shows the original solar cycle F10.7 parametrization in arbitrary units. In the lower panel the residual time series between the measured data and the fitted regression model is shown. The rms for this fit is $0.31 \mathrm{ppmv}$. For further details, see Fig. 3.

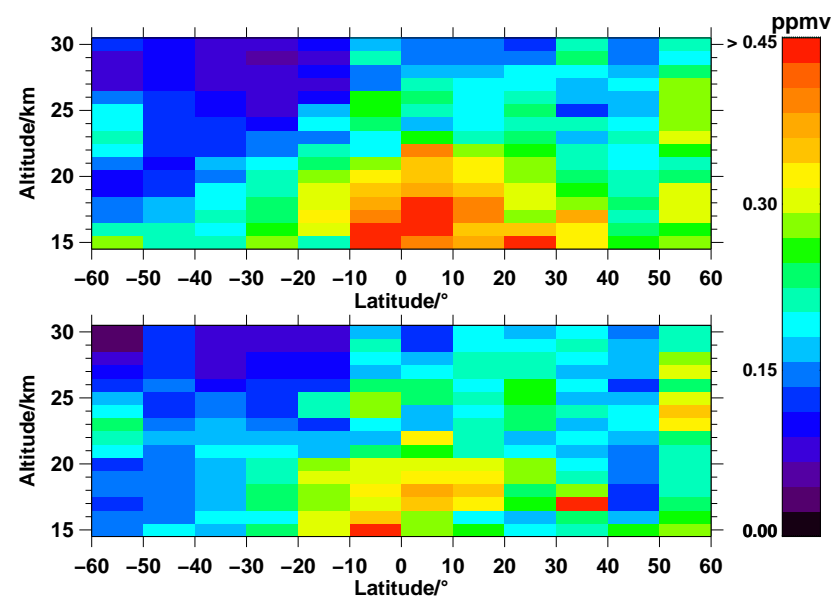

Figure 8. "Quasi-amplitudes" of fitted terms representing the solar cycle in the regression, i.e. the halved differences between the maxima and minima along the time series of these contributions. Top panel: harmonic parametrization; lower panel: F10.7 parametrization.

by Stiller et al. (2012b), which is a measure of the BrewerDobson circulation. This data set, although for a shorter period, is the only available global observational climatology of age of air. Since the age of air changes only slowly (Stiller et al., 2012b), we consider the temporal average for 20022010 as approximately representative for the full period. The increase of the age of air between 18 and $22 \mathrm{~km}$ also is 5 to 10 months, giving the following relation. 


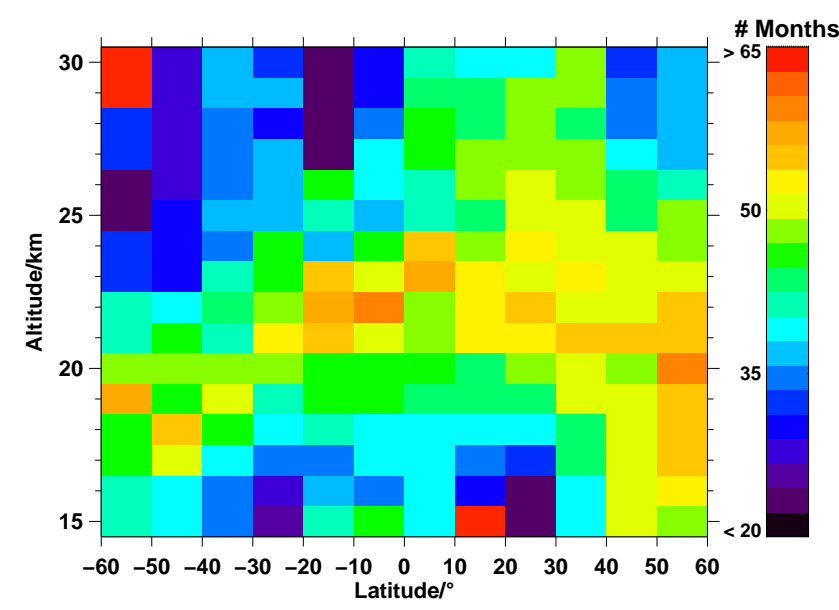

Figure 9. The distribution of the phase shift between the solar maximum and negative water vapour response over latitude and altitude. Positive phase shifts represent a delay of the response of water vapour to the solar cycle.

$\alpha(\phi, z)-\alpha\left(0^{\circ}, 18 \mathrm{~km}\right) \approx \operatorname{age}(\phi, z)-\operatorname{age}\left(0^{\circ}, 18 \mathrm{~km}\right)$

This suggests that the solar effect is not a local one but that part of the phase shift might be caused by transport processes via the upwelling branch of the Brewer-Dobson circulation of a signal generated near the tropical tropopause. Further, the fact that the phase shift is larger than the age of air in the lowermost stratosphere suggests that the effect itself must have an inherent time lag (inh.lag). It can be estimated from the difference of the phase shift of the solar signal and the age of stratospheric air, assuming that the solar perturbation is transported from the tropical tropopause region into the stratosphere by the stratospheric residual circulation:

inh.lag $(\phi, z)=\alpha(\phi, z)-\operatorname{age}(\phi, z)$.

The inherent time lags as a function of latitude and altitude are shown in Fig. 10. We find that for all points below the triangle defined by the points $\left(60^{\circ} \mathrm{S}, 15 \mathrm{~km}\right),\left(0^{\circ}\right.$, $23 \mathrm{~km})$ and $\left(60^{\circ} \mathrm{N}, 15 \mathrm{~km}\right)$ the inherent time lag is almost constant and amounts to roughly 25 months (extrema are 15 and 30 months). A slight decrease of the inherent time lag with altitude, particularly in the tropical pipe, can be explained as follows. It is well-known that the mean age of stratospheric air overestimates the pure transit time of a signal (Birner and Bönisch, 2011) and that in the tropical pipe the discrepancy between age of air and transit time increases with altitude. Thus, the correction by age of air is too large and increases with altitude.

For higher altitudes and latitudes, the phase shift shows a different behaviour. After having reached a maximum in the lower stratosphere (green/yellow belt in Fig. 9), the phase shift becomes smaller again. Moreover the inherent time lag

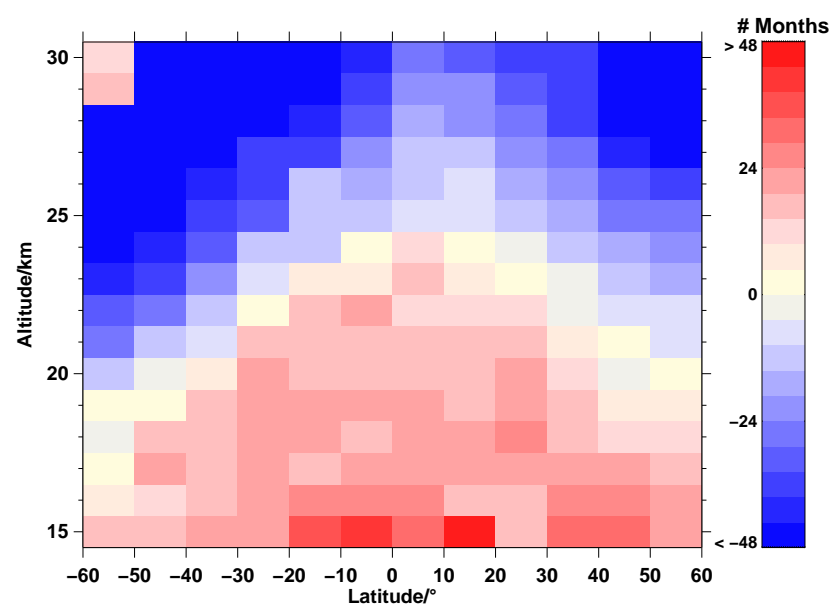

Figure 10. Inherent time lag of the solar signal in water vapour, i.e. difference of the phase shift of the solar signal in water vapour and the age of stratospheric air as derived in Stiller et al. (2012b). Positive values represent delays of the solar signal in water vapour larger than the stratospheric mean age of air.

is negative and decreases further with altitude and latitude. This hints at different processes governing the solar cycle response of water vapour at higher altitudes.

\subsection{Implication for the linear trends and other regression parameters}

Inclusion of a solar cycle by either approach discussed in Sect. 4.2 has improved the fit of the regression model to the measured $\mathrm{H}_{2} \mathrm{O}$ time series. Inclusion of the solar component has largely reduced the systematic residuals of the fit of the time series. When the F10.7 proxy was used, even the millennium drop was - coincidentally or not - modelled much better. Regardless of if a causal relation between solar activity and the lower stratospheric $\mathrm{H}_{2} \mathrm{O}$ distribution is claimed or not, any missing descriptive term in an incomplete regression model causes residuals which are aliased onto other parameters in the fit. In the case discussed here, inclusion of the solar cycle terms leads to much more negative water vapour trends and in some altitude/latitude bins even changes the sign of the trend (Fig. 11). In the standard regression model stratospheric water vapour abundances increase or decrease by less than 0.2 ppmv decade $^{-1}$ nearly everywhere. In particular, a contiguous increase in the lower stratosphere in the order of $0.1-0.2$ ppmv decade $^{-1}$ is seen. When the solar cycle is considered, stratospheric water vapour decreases everywhere, and stronger than by $-0.1 \mathrm{ppmv}$ decade $^{-1}$ at most latitudes and altitudes. This indicates that, even if one does not believe the solar cycle effect in explanatory terms, it still is important in descriptive terms in order to avoid artefacts caused by the related systematic residuals. This means that the related systematic residuals, whatever their cause may be, can emulate artificial trend components. Systematic ef- 


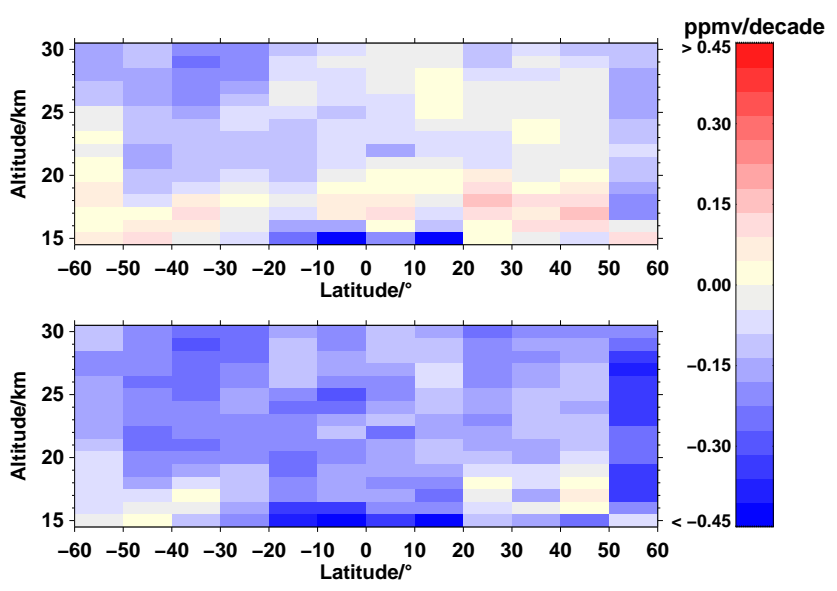

Figure 11. Linear terms of the multivariate regression of water vapour time series with and without the inclusion of a solar term in the regression model. Top panel: standard approach without solar term; lower panel: including F10.7 parametrization.

fects on the annual and semiannual cycles as well as QBO and ENSO amplitudes are much less pronounced.

\section{Discussion}

The analysis of the merged MIPAS-HALOE time series by multivariate linear regression, including a solar cycle proxy as described above, suggests that a solar signal is imprinted on the water vapour abundance entering the stratosphere at the tropical tropopause, and this signal is then transported to the middle stratosphere via the Brewer-Dobson circulation. The signal vanishes in the middle stratosphere. The solar signal in the water vapour time series is phase-shifted anti-correlated to the solar cycle, i.e. lowest water vapour after solar maximum is found. The phase shift consists of two components: the first component is an inherent time lag of about 25 months; the second component results from transport times in the stratosphere by the Brewer-Dobson circulation as approximated by the mean age of air.

Two obvious candidates to explain a solar signal in lower stratospheric water vapour are methane oxidation and the import of water vapour through the tropical tropopause into the stratosphere.

The photochemical oxidation of methane is an important contribution to the stratospheric water vapour budget (le Texier et al., 1988). However, the efficiency of the conversion increases with altitude, and this is opposite to the solar cycle variation observed here (see Fig. 8). The variations of methane in the tropical lower stratosphere are very small (less than $0.1 \mathrm{ppmv}$, not shown here) and not sufficient to explain the observed variation in lower stratospheric water vapour.

The import of water vapour from the troposphere into the stratosphere is to the first order controlled by the tropical cold-point temperature which implies that any mechanism leading to solar cycle influence on the tropical tropopause temperatures could explain the solar cycle signal in water vapour.

Different studies exist that analyse the influence of the solar cycle onto the tropical tropopause temperature with different results: Krüger et al. (2008) investigated NH winters, when the lowest temperatures and water vapour entry values are observed in the lower stratosphere. They used a trajectory model fed with input from ECMWF. In a zonal average they found $0.2 \mathrm{~K}$ higher cold-point temperatures during solar maximum as compared to solar minimum which would contradict our findings. However, over the western Pacific, where most of the air experiences its final dehydration (Fueglistaler et al., 2005), they found a stronger negative temperature anomaly in the order of $1 \mathrm{~K}$ for solar maximum. For solar minimum, a respective positive temperature anomaly of $1 \mathrm{~K}$ was found.

To put these results into context of our observations, we have estimated the temperature variation necessary to produce our observed solar-cycle-driven water vapour variations. Using the relation between temperature and saturation vapour pressure, such $2 \mathrm{~K}$ variation corresponds to a variation in water vapour of about 1 to $1.5 \mathrm{ppmv}$, assuming long-term average temperature conditions for the tropical cold-point tropopause $(\sim 191 \mathrm{~K})$. This would be more than sufficient to explain the solar variation observed in water vapour. However, for temperatures below $187 \mathrm{~K}$, as typical for the $\mathrm{NH}$ winter season, a $2 \mathrm{~K}$ variation would result in water vapour variations that cannot explain the observed variation. In this estimation we explicitly assumed a constant saturation level of $100 \%$, which may be not appropriate.

As a second approach to estimate the temperature variations needed to explain our observed water vapour variations, a regression of observed water vapour variations at the tropical tropopause $\left(\Delta \mathrm{H}_{2} \mathrm{O}\right)$ and variations of approximate coldpoint temperatures $(\Delta T)$, the latter derived from radio occultation observations, were evaluated. This yields the following linear relationship:

$\left\{\Delta \mathrm{H}_{2} \mathrm{O}\right\}_{\mathrm{ppmv}}=0.23 \cdot\{\Delta T\}_{\mathrm{K}}+0.01$,

where curly brackets indicate numerical values. According to these data, the observed solar component of the water vapour variation would require a peak-to-peak cold-point temperature variation of about $3 \mathrm{~K}$, which is larger than the variations found by Krüger et al. (2008).

In contrast to Krüger et al. (2008), Frame and Gray (2010) reported higher temperatures during solar maximum right above the tropical tropopause and lower temperatures right below the tropopause. However, there was no obvious response at the tropopause itself.

Chiodo et al. (2014) used Whole Atmosphere Community Model (WACCM) 3.5 simulations from 1960-2004 to study the solar cycle influence. The analysis indicated that there 
was a positive correlation between solar cycle and stratospheric temperature; however, large parts could be attributed to the alignment of the solar cycle with Pinatubo and El Chichon eruptions. They concluded that it is very difficult to unambiguously assign the variability to the solar cycle. Typically they found a lag of 1 year between the lower stratospheric temperature response and the solar forcing (averaged over $25^{\circ} \mathrm{S}-25^{\circ} \mathrm{N}$ ). This is different from our results where the time lag is much larger. Chiodo et al. (2014) could extract a robust signal only above $10 \mathrm{hPa}$, while below $10 \mathrm{hPa}$, the ambiguity between volcanic influence and solar cycle was too pronounced.

Both the "top-down" solar influence based on solar heating of the stratosphere and the "bottom-up" mechanism (based on solar heating of the sea surface and dynamically coupled air-sea interaction) strengthen the tropical convection and produce an amplified sea surface temperature (SST), precipitation, and cloud response in the tropical Pacific to a relatively small solar forcing (see Meehl et al., 2009; Meehl and Arblaster, 2009). These authors found further that an east Pacific sea surface temperature cooling during the solar maximum is followed by a sea surface temperature warming over wide areas of the Pacific about 2 years later.

According to White et al. (1997) and in agreement with Meehl et al. (2009) and Meehl and Arblaster (2009), globally averaged SST anomalies show highest correlations with solar activity with a phase shift of 1-2 years. White and Liu (2008) found that the eastern tropical Pacific warm phase of the 11-year cycle lagged the peak solar forcing by 1-3 years. All these results are in good agreement with the inherent lag identified in the solar signal in the water vapour time series.

Assuming that the cause of the solar signal seen in water vapour comes from the ocean, Deckert and Dameris (2008a, b) provided an explanation of how the signal is transported from the ocean to the lower stratosphere. Higher sea surface temperatures amplify deep convection locally. The latent heat release from the convection induces pressure perturbations which in turn manifest themselves in the excitation of quasi-stationary planetary waves. These move upwards through the easterly winds, dissipate, but are still strong enough to induce a strengthening of the upwelling. Increased upwelling leads to lower tropopause temperatures and reduced water vapour. Since enhanced sea surface temperatures are found about 2 years after the solar maximum (Meehl et al., 2009; Meehl and Arblaster, 2009), this would explain the water vapour minimum found 2 years after the solar maximum in our study. The cold Pacific during the solar maximum would act towards reduction of upwelling, leading to higher tropopause temperature and higher water vapour concentrations during solar maximum. The process described by Deckert and Dameris (2008a, b) happens during summer (June to September in the Northern Hemisphere and between December and March in the Southern Hemisphere), i.e. not during the times when the Brewer-Dobson circulation is strongest, and at a different season than that ad- dressed by Krüger et al. (2008). This effect is discussed with respect to climate change but their arguments could easily be applied to solar-cycle-induced changes of the sea surface temperature as well.

There is, however, some evidence that weakens the hypothesis of solar-cycle-driven tropopause temperatures, causing the solar signal in lower stratospheric water vapour: Fueglistaler et al. (2013) found a residuum similar to ours between a combined HALOE and MLS time series and trajectory calculations on the basis of several reanalysis data sets. Assuming HALOE data and cold-point temperatures to be correct, this seems to refute the hypothesis that the only mechanism which connects the solar variability with the lower stratospheric water vapour content is the variability of cold-point temperatures with the solar cycle.

Regarding the water vapour trends, there was agreement until recently that water vapour in the lower stratosphere has increased over the previous decades (Oltmans et al., 2000; Rosenlof et al., 2001; Hurst et al., 2011).

Only recently, Hegglin et al. (2014) analysed $\mathrm{H}_{2} \mathrm{O}$ trends of data records obtained with various space-borne limbsounding instruments and found negative trends. Data merging was performed using the Canadian Middle Atmosphere Model 30 (CMAM30) (Scinocca et al., 2008) as a transfer standard. The different temporal coverage of their and our analysis is a major obstacle for direct comparison. Nevertheless, they found negative trends of water vapour in the lower stratosphere in the order of $10 \%$ over 22 years which is somewhat larger than our values, and they attributed this change mainly to an intensification of the shallow branch of the Brewer-Dobson circulation.

The analysis performed by Dessler et al. (2014) was mainly based on the MLS time series and constructed water vapour abundances applying a trajectory model on reanalyses. They found that tropical lower stratospheric water vapour anomalies can fully be described by a multivariate linear regression including the troposphere temperature at $500 \mathrm{hPa}$, a QBO proxy and a proxy of the Brewer-Dobson circulation. With this parametrization no significant linear trend remains.

The findings by Hegglin et al. (2014) and Dessler et al. (2014) neither confirm nor refute our findings. The reasons are these: first, we find it only natural that trends, which by their nature are a descriptive rather than an explaining quantity, are found to be different, depending on which explaining fit parameters are used. Second, the solar cycle might also act upon other atmospheric quantities, which in turn are correlated with the variation of water vapour. In particular, solar influence on both the tropospheric temperature and the Brewer-Dobson circulation was identified (see Gray et al., 2010) which implies that the parametrization chosen by Dessler et al. (2014) has implicitly included a possible solar signal in water vapour. 


\section{Conclusions}

A parametric fit of a 20 -year time series of lower stratospheric water vapour based on a merged MIPAS-HALOE data set is improved by inclusion of a solar cycle term. The water vapour data records within $60^{\circ} \mathrm{S}-60^{\circ} \mathrm{N}$ and 15 to $30 \mathrm{~km}$ are best described by including a solar cycle proxy, implying a phase-shifted anti-correlation between water vapour abundances and solar radiation (i.e. lowest water vapour after solar maximum). Within the lower stratosphere, this phase shift is composed of an almost constant inherent time lag of about 25 months and a variable delay following approximately the age of stratospheric air. Amplitudes of the solar signal in the water vapour time series are largest near the tropical tropopause (up to $0.35 \mathrm{ppmv}$ ) and decrease with altitude and latitude. We propose as an explanation of the behaviour of both the amplitudes and the phase shifts that the solar signal is imprinted on the water vapour, entering the stratosphere through the tropical tropopause, possibly restricted to the western Pacific region and is, thus, a consequence of cold-point temperatures influenced by the solar cycle. The response of lower stratospheric water vapour to the solar cycle suggests that tropopause temperatures relevant for the dehydration of air are lowest about 2 years after solar maximum. Unfortunately, the vertical resolution of conventional satellite-borne temperature sounders available for the time period under assessment is not sufficient for the inference of cold-point temperatures, and radio occultation data have become available only from the year 2000 onwards. Thus, this aspect of our hypothesis cannot be tested.

Inclusion of the solar cycle term in the multivariate linear regression of the water vapour time series has another important consequence: the linear term, interpretable as a trend over the 2 decades of observations, becomes considerably more negative after inclusion of the solar cycle proxy and in the lower stratosphere the "trend" even changes sign from slightly positive without the solar proxy term to significantly negative. Thus, including the solar cycle term as an additional proxy of a driver that rules stratospheric water vapour has the potential to help to resolve the water vapour conundrum: increasing water vapour abundances in the tropical and extra-tropical lowest stratosphere (Rosenlof et al., 2001; Randel et al., 2006) seemed to be in contradiction with observed constant or even slightly decreasing tropical tropopause temperatures (Zhou et al., 2001). The negative net trend derived in our study could help to solve this.
A robust causal ${ }^{1}$ attribution of the lower stratospheric water vapour fluctuations to solar effects is admittedly a challenge because of the small temporal coverage of the time series, which includes less than two solar cycles. But at least it can be said that in descriptive terms the lower stratospheric water vapour time series shows a signal which can be well modelled by a solar cycle signal and whose disregard can affect water vapour trend estimation. Consideration of other $\mathrm{H}_{2} \mathrm{O}$ data sources beyond MIPAS and HALOE and the search for a solar cycle signal in observed cold-point temperatures are suggested as obvious follow-up activities.

Acknowledgements. The provision of MIPAS level-1b data by ESA is gratefully acknowledged. HALOE data were downloaded from http://haloe.gats-inc.com/download/index.php. We acknowledge the HALOE team for their efforts with regard to the instrument operations and the generation and characterization of the HALOE data set. We thank the COSMIC Data Analysis and Archive Center (CDAAC) for the provision of the radio occultation data sets. T. Schieferdecker and S. Lossow were funded by the DFG Research Unit "Stratospheric Change and its Role for Climate Prediction" (SHARP) under contracts STI 210/9-1 and STI 210/9-2. Development of water vapour data retrieval was partly funded by the German Federal Ministry of Education and Research (BMBF) under contract no. 50EE0901.

The article processing charges for this open-access publication were covered by a Research Centre of the Helmholtz Association.

Edited by: M. Dameris

\section{References}

Birner, T. and Bönisch, H.: Residual circulation trajectories and transit times into the extratropical lowermost stratosphere, Atmos. Chem. Phys., 11, 817-827, doi:10.5194/acp-11-817-2011, 2011.

Chiodo, G., Marsh, D. R., Garcia-Herrera, R., Calvo, N., and García, J. A.: On the detection of the solar signal in the tropical stratosphere, Atmos. Chem. Phys., 14, 5251-5269, doi:10.5194/acp-14-5251-2014, 2014.

Connor, B. J., Siskind, D. E., Tsou, J. J., Parrish, A., and Remsberg, E. E.: Ground-based microwave observations of ozone in the upper stratosphere and mesosphere, J. Geophys. Res., 99, 1675716770, doi:10.1029/94JD01153, 1994.

Corti, T., Luo, B. P., de Reus, M., Brunner, D., Cairo, F., Mahoney, M. J., Martucci, G., Matthey, R., Mitev, V., Silva dos Santos,

\footnotetext{
${ }^{1}$ It is a general truism that statistical co-occurrence never assures a causal relation, but we can neither imagine that Earth's atmosphere affects solar activity or that both lower stratospheric water vapour and solar activity are controlled by a third driver. Thus we consider pure coincidence, caused by other processes of a similar timescale, e.g. variability in the ocean / atmosphere system with coincidently similar periods and time phases, as the only serious alternative hypothesis.
} 
F. H., Schiller, C., Shur, G., Sitnikov, N. M., Spelten, N., Vössing, H. J., Borrmann, S., and Peter, T.: Unprecedented evidence for deep convection hydrating the tropical stratosphere, Geophys. Res. Lett., 35, L10810, doi:10.1029/2008GL033641, 2008.

Cunnold, D. M., Yang, E.-S., Newchurch, M. J., Reinsel, G. C., Zawodny, J. M., and Russell III, J. M.: Comment on "Enhanced upper stratospheric ozone: Sign of recovery or solar cycle effect?" by W. Steinbrecht et al., J. Geophys. Res., 109, D14305, doi:10.1029/2004JD004826, 2004.

Deckert, R. and Dameris, M.: Higher tropical SSTs strengthen the tropical upwelling via deep convection, Geophys. Res. Lett., 35, L10813, doi:10.1029/2008GL033719, 2008a.

Deckert, R. and Dameris, M.: From ocean to stratosphere, Science, 322, 53-55, doi:10.1126/science.1163709, 2008b.

Dessler, A. E. and Kim, H.: Determination of the amount of water vapor entering the stratosphere based on Halogen Occultation Experiment, J. Geophys. Res., 104, 30605-30607, 1999.

Dessler, A. E., Schoeberl, M. R., Wand, T., Davis, S. M., Rosenlof, K. H., and Vernier, J.: Variations of stratospheric water vapor over the past three decades, J. Geophys. Res., 119, 12588-12598, doi:10.1002/2014JD021712, 2014.

Fischer, H., Birk, M., Blom, C., Carli, B., Carlotti, M., von Clarmann, T., Delbouille, L., Dudhia, A., Ehhalt, D., Endemann, M., Flaud, J. M., Gessner, R., Kleinert, A., Koopman, R., Langen, J., López-Puertas, M., Mosner, P., Nett, H., Oelhaf, H., Perron, G., Remedios, J., Ridolfi, M., Stiller, G., and Zander, R.: MIPAS: an instrument for atmospheric and climate research, Atmos. Chem. Phys., 8, 2151-2188, doi:10.5194/acp-8-2151-2008, 2008.

Frame, T. H. A. and Gray, L. J.: The 11-year solar cycle in ERA-40 data: An update to 2008, J. Climate, 23, 2213-2222, doi:10.1175/2009JCLI3150.1, 2010.

Froidevaux, L., Anderson, J., Wang, H.-J., Fuller, R. A., Schwartz, M. J., Santee, M. L., Livesey, N. J., Pumphrey, H. C., Bernath, P. F., Russell III, J. M., and McCormick, M. P.: Global OZone Chemistry And Related Datasets for the Stratosphere (GOZCARDS): methodology and sample results with a focus on $\mathrm{HCl}$, $\mathrm{H}_{2} \mathrm{O}$, and $\mathrm{O}_{3}$, Atmos. Chem. Phys. Discuss., 15, 5849-5957, doi:10.5194/acpd-15-5849-2015, 2015.

Fueglistaler, S.: Stepwise changes in stratospheric water vapor?, J. Geophys. Res., 117, D13302, doi:10.1029/2012JD017582, 2012.

Fueglistaler, S., Bonazzola, M., Haynes, P. H., and Peter, T.: Stratospheric water vapor predicted from the Lagrangian temperature history of air entering the stratosphere in the tropics, J. Geophys. Res., 110, D08107, doi:10.1029/2004JD005516, 2005.

Fueglistaler, S., Dessler, A. E., Dunkerton, T. J., Folkins, I., Fu, Q., and Mote, P. W.: Tropical Tropopause Layer, Rev. Geophys., 47, RG1004, doi:10.1029/2008RG000267, 2009.

Fueglistaler, S., Liu, Y. S., Flannaghan, T. J., Haynes, P. H., Dee, D. P., Read, W. J., Remsberg, E. E., Thomason, L. W., Hurst, D. F., Lanzante, J. R., and Bernath, P. F.: The relation between atmospheric humidity and temperature trends for stratospheric water, J. Geophys. Res., 118, 1052-1074, doi:10.1002/jgrd.50157, 2013.

Gray, L. J., Beer, J., Geller, M., Haigh, J. D., Lockwood, M., Matthes, K., Cubasch, U., Fleitmann, D., Harrison, G., Hood, L., Luterbacher, J., Meehl, G. A., Shindell, D., van Geel, B., and White, W.: Solar influences on climate, Rev. Geophys., 48, RG4001, doi:10.1029/2009RG000282, 2010.
Harries, J. E., Russell III, J. M., Tuck, A. F., Gordley, L. L., Purcell, P., Stone, K., Bevilacqua, R. M., Gunson, M., Nedoluha, G., and Traub, W. A.: Validation of measurements of water vapor from the Halogen Occultation Experiment (HALOE), J. Geophys. Res., 101, 10205-10216, 1996.

Hegglin, M. I., Tegtmeier, S., Anderson, J., Froidevaux, L., Fuller, R., Funke, B., Jones, A., Lingenfelser, G., Lumpe, J., Pendlebury, D., Remsberg, E., Rozanov, A., Toohey, M., Urban, J., von Clarmann, T., Walker, K. A., Wang, R., and Weigel, K.: SPARC Data Initiative: Comparison of water vapor climatologies from international satellite limb sounders, J. Geophys. Res.-Atmos., 118, 11824-11846, doi:10.1002/jgrd.50752, 2013.

Hegglin, M. I., Plummer, D. A., Shepherd, T. G., Scinocca, J. F., Anderson, J., Froidevaux, L., Funke, B., Hurst, D., Rozanov, A., Urban, J., von Clarmann, T., Walker, K. A., Wang, H. J., Tegtmeier, S., and Weigel, K.: Vertical structure of stratospheric water vapour trends derived from merged satellite data, Nat. Geosci., 7, 768-776, doi:10.1038/ngeo2236, 2014.

Hervig, M. E., Russell III, J. M., Gordley, L. L., Daniels, J., Drayson, S. R., and Park, J. H.: Aerosol effects and corrections in the Halogen Occultation Experiment, J. Geophys. Res., 100, 1067-1079, 1995.

Holton, J. R. and Gettelmann, A.: Horizontal transport and the dehydration of the stratosphere, Geophys. Res. Lett., 28, 2799-2802, 2001.

Hurst, D. F., Oltmans, S. J., Vömel, H., Rosenlof, K. H., Davis, S. M., Ray, E. A., Hall, E. G., and Jordan, A. F.: Stratospheric water vapor trends over Boulder, Colorado: Analysis of the 30 year Boulder record, J. Geophys. Res., 116, D02306, doi:10.1029/2010JD015065, 2011.

Jones, A., Urban, J., Murtagh, D. P., Eriksson, P., Brohede, S., Haley, C., Degenstein, D., Bourassa, A., von Savigny, C., Sonkaew, T., Rozanov, A., Bovensmann, H., and Burrows, J.: Evolution of stratospheric ozone and water vapour time series studied with satellite measurements, Atmos. Chem. Phys., 9, 6055-6075, doi:10.5194/acp-9-6055-2009, 2009.

Kiehl, J. T. and Trenberth, K. E.: Earth's Annual Global Mean Energy Budget, B. Am. Meteorol. Soc., 78, 197-208, 1997.

Kley, D., Russell III, J. M., and Phillips, C. (Eds.): Stratospheric Processes and their Role in Climate (SPARC) - Assessment of upper tropospheric and stratospheric water vapour, WCRP No. 113, WMO/TD - No. 1043, SPARC Report No. 2, WMO/ICSU/IOC, Paris, 2000.

Krüger, K., Tegtmeier, S., and Rex, M.: Long-term climatology of air mass transport through the Tropical Tropopause Layer (TTL) during NH winter, Atmos. Chem. Phys., 8, 813-823, doi:10.5194/acp-8-813-2008, 2008.

Kyrölä, E., Tamminen, J., Leppelmeier, G. W., Sofieva, V., Hassinen, S., Bertaux, J. L., Hauchecorne, A., Dalaudier, F., Cot, C., Korablev, O., Fanton d'Andon, O., Barrot, G., Mangin, A., Théodore, B., Guirlet, M., Etanchaud, F., Snoeij, P., Koopman, R., Saavedra, L., Fraisse, R., Fussen, D., and Vanhellemont, F.: GOMOS on Envisat: an overview, Adv. Space Res., 33, 1020 1028, doi:10.1016/S0273-1177(03)00590-8, 2004.

le Texier, H., Solomon, S., and Garcia, R. R.: The role of molecular hydrogen and methane oxidation in the water vapour budget of the stratosphere, Q. J. Roy. Meteorol. Soc., 114, 281-295, 1988. 
Manabe, S. and Strickler, R. F.: Thermal equilibrium of the atmosphere with a convective adjustment, J. Atmos. Sci., 21, 361-385, 1964.

Meehl, G. A. and Arblaster, J. M.: A lagged warm event-like response to peaks in solar forcing in the pacific region, J. Climate, 22, 3647-3660, doi:10.1175/2009JCLI2619.1, 2009.

Meehl, G. A., Arblaster, J. M., Matthes, K., Sassi, F., and van Loon, H.: Amplifying the Pacific climate system response to a small 11-year solar cycle forcing, Science, 325, 1114-1118, 2009.

Milz, M., von Clarmann, T., Fischer, H., Glatthor, N., Grabowski, U., Höpfner, M., Kellmann, S., Kiefer, M., Linden, A., Mengistu Tsidu, G., Steck, T., Stiller, G. P., Funke, B., López-Puertas, M., and Koukouli, M. E.: Water Vapor Distributions Measured with the Michelson Interferometer for Passive Atmospheric Sounding on board Envisat (MIPAS/Envisat), J. Geophys. Res., 110, D24307, doi:10.1029/2005JD005973, 2005.

Milz, M., Clarmann, T. v., Bernath, P., Boone, C., Buehler, S. A., Chauhan, S., Deuber, B., Feist, D. G., Funke, B., Glatthor, N., Grabowski, U., Griesfeller, A., Haefele, A., Höpfner, M., Kämpfer, N., Kellmann, S., Linden, A., Müller, S., Nakajima, H., Oelhaf, H., Remsberg, E., Rohs, S., Russell III, J. M., Schiller, C., Stiller, G. P., Sugita, T., Tanaka, T., Vömel, H., Walker, K., Wetzel, G., Yokota, T., Yushkov, V., and Zhang, G.: Validation of water vapour profiles (version 13) retrieved by the IMK/IAA scientific retrieval processor based on full resolution spectra measured by MIPAS on board Envisat, Atmos. Meas. Tech., 2, 379-399, doi:10.5194/amt-2-379-2009, 2009.

Nedoluha, G. E., Bevilacqua, R. M., Gomez, R. M., Hicks, B. C., Russell III, J. M., and Connor, B. J.: An evolution of trends in middle atmospheric water vapor as measured by HALOE, WVMS, and POAM, J. Geophys. Res., 108, 4391, doi:10.1029/2002JD003332, 2003.

Nedoluha, G. E., Gomez, R. M., Allen, D. R., Lambert, A., Boone, C. D., and Stiller, G. P.: Variations in middle atmospheric water vapor from 2004 to 2013, J. Geophys. Res.-Atmos., 118, 1128511293, doi:10.1002/jgrd.50834, 2013.

Oltmans, S. J., Vömel, H., Hofmann, D. J., Rosenlof, K. H., and Kley, D.: The increase in stratospheric water vapor from ballooneborne, frostpoint hygrometer measurements at Washington, D.C., and Boulder, Colorado, Geophys. Res. Lett., 27, 34533456, 2000.

Randel, W. J., Wu, F., Vömel, H., Nedoluha, G. E., and Forster, P.: Decreases in stratospheric water vapor after 2001: Links to changes in the tropical tropopause and the Brewer-Dobson circulation, J. Geophys. Res., 111, D12312, doi:10.1029/2005JD006744, 2006.

Reinsel, G. C.: Trend analysis of upper stratospheric Umkehr ozone data for evidence of turnaround, Geophys. Res. Lett., 29, 1451, doi:10.1029/2002GL014716, 2002.

Riese, M., Ploeger, F., Rap, A., Vogel, B., Konopka, P., Dameris, M., and Forster, P.: Impact of uncertainties of atmospheric mixing on simulated UTLS composition and related radiative effects, J. Geophys. Res., 117, D16305, doi:10.1029/2012JD017751, 2012.

Rodgers, C. D.: Inverse Methods for Atmospheric Sounding: Theory and Practice, Vol. 2 of Series on Atmospheric, Oceanic and Planetary Physics, edited by: Taylor, F. W., World Scientific, Singapore, New Jersey, London, Hong Kong, 2000.

Rosenlof, K. H. and Reid, G. C.: Trends in the temperature and water vapor content of the tropical lower strato- sphere: Sea surface connection, J. Geophys. Res., 113, D06107, doi:10.1029/2007JD009109, 2008.

Rosenlof, K. H., Oltmans, S. J., Kley, D., Russell III, J. M., Chiou, E.-W., Chu, W. P., Johnson, D. G., Kelly, K. K., Michelsen, H. A., Nedoluha, G. E., Remsberg, E. E., Toon, G. C., and McCormick, M. P.: Stratospheric water vapor increases over the past halfcentury, Geophys. Res. Lett., 28, 1195-1198, 2001.

Russell III, J. M.: HALOE level 2 data description, available at: http://badc.nerc.ac.uk/browse/badc/haloe/doc/haloe_12.sfdu (last access: 1 June 2014), 1995.

Russell III, J. M., Gordley, L. L., Park, J. H., Drayson, S. R., Hesketh, W. D., Cicerone, R. J., Tuck, A. F., Frederick, J. E., Harries, J. E., and Crutzen, P. J.: The Halogen Occultation Experiment, J. Geophys. Res., 98, 10777-10797, 1993.

Schieferdecker, T.: Variabilität von Wasserdampf in der unteren und mittleren Stratosphäre auf der Basis von HALOE/UARS und MIPAS/Envisat Beobachtungen, PhD thesis, Karlsruhe Institute of Technology, available at: http://digbib.ubka.uni-karlsruhe.de/ volltexte/1000046296, last access: 10 March 2015.

Schiller, C., Grooß, J.-U., Konopka, P., Plöger, F., Silva dos Santos, F. H., and Spelten, N.: Hydration and dehydration at the tropical tropopause, Atmos. Chem. Phys., 9, 9647-9660, doi:10.5194/acp-9-9647-2009, 2009.

Scinocca, J. F., McFarlane, N. A., Lazare, M., Li, J., and Plummer, D.: Technical Note: The CCCma third generation AGCM and its extension into the middle atmosphere, Atmos. Chem. Phys., 8, 7055-7074, doi:10.5194/acp-8-7055-2008, 2008.

Solomon, S., Rosenlof, K. H., Portmann, R. W., Daniel, J. S., Davis, S. M., Sanford, T. J., and Plattner, G.-K.: Contributions of Stratospheric Water Vapor to Decadal Changes in the Rate of Global Warming, Science, 327, 1219-1223, doi:10.1126/science.1182488, 2010.

Steele, H. M. and Turco, R. P.: Separation of aerosol and gas components in the Halogen Occultation Experiment and the Stratospheric Aerosol and Gas Experiment (SAGE) II extinction measurements: Implication for SAGE II ozone concentrations and trends, J. Geophys. Res., 102, 19665-19681, 1997.

Stenke, A. and Grewe, V.: Simulation of stratospheric water vapor trends: impact on stratospheric ozone chemistry, Atmos. Chem. Phys., 5, 1257-1272, doi:10.5194/acp-5-1257-2005, 2005.

Stiller, G. P., Kiefer, M., Eckert, E., von Clarmann, T., Kellmann, S., García-Comas, M., Funke, B., Leblanc, T., Fetzer, E., Froidevaux, L., Gomez, M., Hall, E., Hurst, D., Jordan, A., Kämpfer, N., Lambert, A., McDermid, I. S., McGee, T., Miloshevich, L., Nedoluha, G., Read, W., Schneider, M., Schwartz, M., Straub, C., Toon, G., Twigg, L. W., Walker, K., and Whiteman, D. N.: Validation of MIPAS IMK/IAA temperature, water vapor, and ozone profiles with MOHAVE-2009 campaign measurements, Atmos. Meas. Tech., 5, 289-320, doi:10.5194/amt-5-289-2012, 2012a.

Stiller, G. P., von Clarmann, T., Haenel, F., Funke, B., Glatthor, N., Grabowski, U., Kellmann, S., Kiefer, M., Linden, A., Lossow, S., and López-Puertas, M.: Observed temporal evolution of global mean age of stratospheric air for the 2002 to 2010 period, Atmos. Chem. Phys., 12, 3311-3331, doi:10.5194/acp-12-33112012, $2012 b$.

Urban, J., Lossow, S., Stiller, G., and Read, W.: Another drop in water vapor, Eos T. Am. Geophys. Un., 95, 245-246, doi:10.1002/2014EO270001, 2014. 
von Clarmann, T., Glatthor, N., Grabowski, U., Höpfner, M., Kellmann, S., Kiefer, M., Linden, A., Mengistu Tsidu, G., Milz, M., Steck, T., Stiller, G. P., Wang, D. Y., Fischer, H., Funke, B., Gil-López, S., and López-Puertas, M.: Retrieval of temperature and tangent altitude pointing from limb emission spectra recorded from space by the Michelson Interferometer for Passive Atmospheric Sounding (MIPAS), J. Geophys. Res., 108, 4736, doi:10.1029/2003JD003602, 2003.

von Clarmann, T., Höpfner, M., Kellmann, S., Linden, A., Chauhan, S., Funke, B., Grabowski, U., Glatthor, N., Kiefer, M., Schieferdecker, T., Stiller, G. P., and Versick, S.: Retrieval of temperature, $\mathrm{H}_{2} \mathrm{O}, \mathrm{O}_{3}, \mathrm{HNO}_{3}, \mathrm{CH}_{4}, \mathrm{~N}_{2} \mathrm{O}, \mathrm{ClONO}_{2}$ and $\mathrm{ClO}$ from MIPAS reduced resolution nominal mode limb emission measurements, Atmos. Meas. Tech., 2, 159-175, doi:10.5194/amt-2-159-2009, 2009. von Clarmann, T., Stiller, G., Grabowski, U., Eckert, E., and Orphal, J.: Technical Note: Trend estimation from irregularly sampled, correlated data, Atmos. Chem. Phys., 10, 6737-6747, doi:10.5194/acp-10-6737-2010, 2010.

White, W. B. and Liu, Z.: Resonant excitation of the quasi-decadal oscillation to the 11-yr period signal in the Sun's irradiance, J Geophys. Res., 113, C01002, doi:10.1029/2006JC004057, 2008.

White, W. B., Lean, J., Cayan, D. R., and Dettinger, M. D.: Response of global upper ocean temperature to changing solar irradiance, J. Geophys. Res., 102, 3255-3266, doi:10.1029/96JC03549, 1997.

Zhou, X.-L., Geller, M. A., and Zhang, M.: Cooling trend of the tropical cold point tropopause temperatures and its implications, J. Geophys. Res, 106, 1511-1522, doi:10.1029/2000JD900472, 2001. 